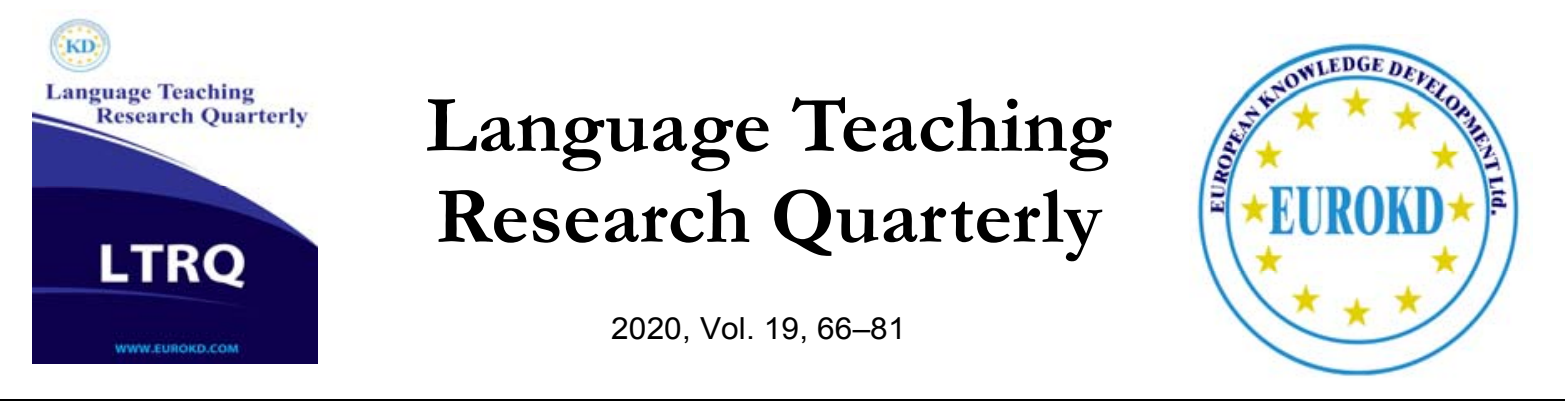

\title{
Preventing Attrition and Promoting Retention
}

\author{
Kathleen Bardovi- Harlig*, Beatrix Burghardt \\ Indiana University, USA
}

Special Issue: Pathways to the Successful Teaching and Learning of an L2

In Honor of Andrew Cohen's Contributions to L2 Teaching and Learning Research

Received 15 November $2019 \quad$ Accepted 24 April 2020

\begin{abstract}
This paper discusses the stage of second language acquisition known as attrition and what learners and teachers can do to prevent attrition and promote retention. Attrition is the stage at which a learner's attained proficiency declines due to a reduction of contact with the second language, whether from lack of contact with other speakers of the language, cessation of language instruction, or a number of other factors. The paper briefly summarizes research on language attrition, then reviews a prototype program developed to encourage L2 retention for a specific learner population, and discusses a range of activities in which learners at large may engage to promote retention of their L2 knowledge, including both traditional and technology-mediated activities. The paper also suggests means by which language teachers may prepare their students for the possibility of attrition and help them develop skills for independent learning and engaging with language activities and resources that will facilitate language retention.
\end{abstract}

Keywords: Attrition, Retention, Input, Motivation, Technology-mediated language learning resources

\section{Introduction}

In this paper we discuss second language attrition and its counterpart, second language retention. Second language attrition is the diminishment of language competence overtime, generally involving a reduction in input and a concomitant expectation of language use. Second/foreign language attrition was first discussed in language learning and teaching literature out of a concern for potential loss of language knowledge and skills over summer vacation, during which 
learners experience a reduction or complete cessation of contact with the second or foreign language being learned. Attrition can begin in a number of situations and is a natural part of the cycle of language acquisition. The super-hero nemesis of attrition is retention, and that is the focus of this article.

As Cohen (2018) has noted, more energy goes into helping learners acquire language than to maintain what they have acquired, and he suggests that it would be equally worthwhile to alert teachers and learners to strategies for preventing attrition. We take up the challenge with an initial attempt to address this issue. In the next section we will define terms and concepts used to investigate language attrition and review some basic findings that are relevant to language retention and relearning. We then lay out principles for language pedagogy designed to promote retention, and then suggest both traditional and technology-mediated activities in which learners can engage to keep their L2 activated. Throughout we will assume that our target learner/potential attriter/active retainer is an adult learner of at least high school or college age.

\section{Attrition and Retention}

In this section we introduce the terms that we will use throughout the paper. In this paper we will discuss language attrition as the diminishing of proficiency in an individual as a result of reduced contact with the target language. The verb for losing one's language is attrite and we will call people in the process of attriting attriters. Learners or L2 speakers might be at risk for attrition when situations change such that they are no longer in daily contact with the target language or community (including classrooms as communities). Daily language contact may be reduced when students graduate, semesters come to an end, requirements are fulfilled, sabbaticals are over, students return from study abroad, employees get transferred, missions are concluded, troops get reassigned, students and their families return from graduate programs abroad, or other events take people from richer language environments to more impoverished ones. Even if learners who return from study abroad re-enroll in foreign language classes, the language classroom can nevertheless constitute a reduction in opportunities to receive input and expectations for production. Even when students return to a classroom as advanced language learners, they may still be at risk for language attrition (Bardovi-Harlig \& Stringer, 2010). Circumstances may also be less dramatic; many studies have included investigations of attrition by students during summer vacation (Cohen, 1974, 1975).

The opposite of language attrition is language retention, which we will define as the conscious engagement in activities that will slow or impede attrition. We will call speakers and learners who are consciously undertaking activities to avoid attrition and promote retention retainers. As with our definition of attrition, we see at least two parts to retention: maintaining or creating opportunities for both input and production. By the latter, production, we mean the expectation of production that arises through the meaningful communication with others, not the mere articulation of utterances for practice. In the attrition literature there is also the notion of relearning, i.e., the learning of an L2 or parts of an L2 that one has lost (de Bot \& Stoessel, 2000; Hansen, Umeda, \& McKinney, 2002). Some researchers have suggested that learning a 
second time, or relearning, is faster than initial acquisition because relearning leads to reactivation of the previously learned language (Clark \& Jorden, 1984; Russell, 1999). The goal of retention is to avoid loss, and thus also avoid relearning, if possible.

The basic principle of retention is to avoid removing oneself from language input and the expectation of language use or the environment in which the target language is spoken. However, this is not always possible because any number of life events take L2 speakers and learners from a rich language environment to an environment that either has reduced opportunities for language use or no local opportunities. It is at that point that retention opportunities become valuable. The retention process requires both motivation and effort on the part of learners-asretainers: "language retention is always a conscious act that involves the seeking out of opportunities for second language input and use when the natural involvement in both has ceased" (Ludwig, Fu, Bardovi-Harlig, \& Stringer, 2009, p. 4).

Motivation researchers have suggested that motivation plays a significant role in retention (Gardner, Lalonde, \& MacPherson, 1985; Gardner, Lalonde, Moorcroft, \& Evers, 1987; Cohen, 2010, 2018). Dörnyei and Ushioda (2013) explain that motivation entails three elements, "the choice of a particular action, the persistence with it, and the effort expended on it", and these explain "why [...], how long [...], how hard" learners are going to engage with a chosen activity (p.3, italics in original).Recent motivation research that has explored autonomous learning behavior in language learning and learning effort (e.g., Csizér \& Dörnyei, 2005; Kormos \& Csizér, 2014) is particularly relevant to cases of retention, and consequently to the retention activities we propose here because in most cases of attrition, an individual no longer has contact with an instructor or a relevant target language community and thus is on his or her own. Kormos and Csizér (2014) have identified autonomous learning as an independent variable in motivation for language acquisition. Moreover, they found that looking for traditional learning resources and using learning technology are influenced by different factors. They report that "efficient management of time and boredom, as well as proactivity in seeking learning opportunities" were necessary to "promote autonomous use of traditional learning resources." In contrast, these were not as important with autonomous use of technology where "a proactive approach to locating and using these learning resources is necessary" (p. 275). Thus, introducing learners to materials for autonomous use that include both traditional and technology-based resources may reach different individuals.

\section{A Summary of Classic Studies on Attrition}

Before addressing the focus of this article, which is to consider how to thwart the process of attrition, promote retention, and consider how learners might be able to go about it, we review some of the findings of the classic literature on attrition (Bardovi-Harlig \& Stringer, 2010, pp. 24-25, reordered and simplified here).

1. Production (speaking and writing) is more vulnerable than listening and reading.

2. Attrition is often signaled by reduced fluency (including a reduction in words per minute as well as other measures). 
3. Literacy impedes attrition (and supports retention); i.e., readers are better off than nonreaders.

4. The lexicon is more likely to show effects of attrition than grammar (on the other hand, there is no grammar without vocabulary).

5. Decrease in vocabulary (from either reduction in size of vocabulary or reduced access to the vocabulary).

6. Motivation is implicated in both language learning and attrition.

7. Continued language education supports retention.

8. Lower level learners are more likely to attrite than higher level learners.

The effects of attrition are stated in terms of both features of grammar and skills. In grammar, the lexicon is more likely to show attrition than phonology and syntax; a decrease in vocabulary is likely whether measured in size and diversity (number of words used, Cohen, 1986 or number of different words, Cohen, 1989) or access (Cohen, 1989).Among the skills, production is more likely to show the effects of attrition than listening and reading, and oral production may show a reduction in fluency as measured by rate of speech. Other findings point to factors that may retard attrition (or promote retention) including higher levels of proficiency, ability to read in the target language, continued language education, and motivation. These findings suggest potential targets for retention as well as advantages that may be exploited in task development. Before we move on to our own suggestions, we consider a set of retention activities designed and tested by computer scientists, Drs. Jeremy Ludwig and Dan Fu, and reported in Ludwig et al. (2009).

\section{An Example of an L2 Retention Prototype}

The L2 retention prototype reviewed here was developed to assist military personnel to retain L2 proficiency gained before or during in-country deployment while relocated for additional nonlanguage training. It should be noted that the period of additional training away from the target language setting - and thus the period for potential attrition or retention - was finite and that the troops for whom the retention activities were designed were scheduled to return to the targetlanguage region. Prototype retention game-based programs were created because no software specifically targeted at retention was available at the time. Ludwig et al. (2009) made three fundamental pedagogical recommendations (pp. 4-5): (a) Retention activities should focus on supporting implicit knowledge — knowledge of the language — rather than explicit knowledgeknowledge about the language; (b) Retention activities should emphasize learner production whenever possible (recall that production is at greater risk for attrition than receptive abilities); and (c) Retention activities should not just review what learners have acquired, but should offer learners the opportunity to learn more (call this review plus). A strict review-only approach may not be possible if designing or recommending retention activities to be used by more than one learner because learners vary greatly in what they acquire even with the same input, so broad targets may be necessary. Moreover, in addition to the practical considerations of identifying strict review-only content, Ludwig et al. argue that implementing a review plus approach has a number of potential advantages: "introduction of novel but related material helps (1) linguistic 
systems become better anchored, (2) reduces potential boredom with a closed set of content, (3) increases challenge and competition (with self and others) for gaming and self-study, offering users the opportunity to reach higher levels, (4) allows multiple words, expressions, and structures for ease of retrieval, (5) increases confidence in language use in multiple settings, and (6) accommodates a learner population at multiple levels of competence" (p. 5).

The troops for whom the retention module was created were expected to have access to only hand-held devices such as phones. As a result, Ludwig and $\mathrm{Fu}$ designed prototypes for four games that could be played on the 2009 model iPhone and that took advantage of the touch screen, direction sensors, and wi-fi connections that allowed multi-player versions of two of the games. These were a trivia game involving naming and translation (with single and multi-player options), a video enactment, a word-order game in which players move words on the screen to create grammatical sentences (and receive feedback, if incorrect), and the most challenging, a maze in which players move through a pinball-like maze encountering barriers which are easy, intermediate, and difficult language questions or problems in both a single- and multi-player format. Player scores are based on correctness and speed. Players compete with other players either directly in multi-player formats or through scores posted via the internet for other players to see. Scores and competition were seen as additional motivation to play the games as were the possibilities for advancing to different levels within the games (particularly in the maze), which was intended to keep the retainers playing the game.

The average learner at risk for attrition differs from military personnel in that they are unlikely to have a cohort, that is, most language learners seeking retention activities are likely to be on their own rather than with others in the same situation. Not all learners (or employers of learners) can commission the development of retention activities and games by computer scientists and attrition/acquisition researchers. In the sections that follow we propose retention activities that can be undertaken by a range of retainers (learners desiring to retain their language proficiency) and that are available both in the real world and online, using the principles suggested by Ludwig et al. (2009).

\section{From Attrition to Retention: Activities}

Kormos and Csizér (2014) identify motivation to engage in autonomous learning as a component of language learning motivation, and moreover they suggest that using traditional resources and technology-based resources are motivated by different factors. In this discussion we follow Kormos and Csizér by dividing our suggestions for continued engagement with the language into "traditional" activities in which we include face-to-face and community interactions, and technology-based resources and interactions. ${ }^{i}$ We also take a certain liberty with their framework by extending it to autonomous learning after instruction has concluded which was not the context in which the distinction was proposed, and additionally grouping all retainers together as potential beneficiaries. We note that learners who have established autonomous learning practices to supplement classroom language learning are very likely to be better positioned to continue to use them to enhance retention or to expand their engagement. Finally, the 
suggestions that we make have not yet been tested for efficacy; we return to the need for what would resemble "instructional effect studies" for retention in the final section of the paper.

Because a language learner who is at greatest risk of attrition is unlikely to have access to a teacher (at least in the traditional sense), we will focus on activities that retainers can do on their own. We will consider the advantages of both traditional and technology-mediated activities, and we will take the position that mere repetition or practice of only what is known will be less motivating to learners than activities which allow them to continue to learn by focusing on communication. It is also important to balance tasks that do not require production with tasks that do.

\section{Traditional Resources and Activities}

Engagement with other speakers not only provides additional opportunities for input, it obligates the retainer to produce language, a desirable outcome because production is at greater risk for attrition. To that end, retainers may undertake community service in which speakers of the target-language are also engaged, join clubs known for bilingual or multilingual members, seek out coffee houses or cafes which cater to speakers of the L2, or establish a conversation group or a tandem learning partnership. Writing to pen pals (with or without computer mediation) is a time-honored tradition.

There are also a range of traditional resources. These include, for example, listening to the radio (whether live or podcasts) or watching television and movies. If one attends movies in a theater, one might strike up a conversation with others who are speaking the target language by commenting on the movie. We realize that this suggestion might horrify some retainers. In one undergraduate SLA class that we taught, students who completed a willingness to communicate survey as part of a class activity overwhelmingly reported that they would not talk to other people in line waiting for an event (such as a movie or a show) even in their native language. Thus, engagement may not be for everyone.

For those who prefer solitary activities, reading for pleasure also supports retention (as it does acquisition); reading materials include both fiction and nonfiction, and come in a variety of forms including magazines, books, graphic novels, and bilingual books. ${ }^{\text {ii }}$ A retainer may also want to consult a dictionary. The benefits of extensive reading for acquisition are well known, and Day and Bamford (1998) argue that it increases motivation as well as language proficiency. Empirical studies have shown that reading modified literature leads L2 learners to increases in reading fluency and automaticity, comprehension and vocabulary knowledge while also furthering their motivation to read (Al-Homoud \& Schmitt, 2009; Grabe \& Stoller, 2002).Although extensive reading is a curricular notion developed for classroom instruction, it has an out-of-class equivalent known as 'pleasure reading,' which can be undertaken by retainers.

Comic strips, graphic novels, and graphic stories (here grouped into one category) are gaining in popularity cross-culturally and they vary in content: some are created with the purpose of entertainment, while others are used in college courses to deliver content. Independent of their 
function, they all integrate text, image, and sound (in spelled-out form). Research in tertiary science, history, and business courses has shown the motivating power of these materials to engage with content learning, in comparison to textbook-based teaching (Hosler \& Boomer, 2011). From a linguistic perspective, comic books are valuable because they tell stories through interaction between characters using authentic, spoken language, and the texts are rich in fixed expressions (Williams, 1995).Comic books are shorter, on average, than most adult books, and yet they expose readers to a roughly equivalent rate of low-frequency words as books for adults (53.5 low-frequency words per 1000 words for comic books and 52.7/1000 words for adult books; this contrasts with children's books at30.9 rare words/1000; The Center on Teaching and Learning, University of Oregon, http://reading.uoregon.edu/big ideas/voc/voc what.php).The juxtaposition of the image and the text potentially helps the learner decode "the meaning of an unfamiliar word or grammatical structure" (Krashen, 1989, p. 402, as cited in Chun, 2009). Empirical studies in L2 classrooms have shown the same positive motivational power of these materials as in L1 content-classes and, in addition, increased outcomes obtained in reading comprehension and vocabulary acquisition, including idioms, in studies with intermediate proficiency L2 learners (Başal, Aytan, Demir, 2016; Liu, 2004; Ludewig, 2017). Chun (2009) also suggests that content-based graphic novels are appropriate for high-intermediate learners.

Distinct from pleasure reading, dictionaries are a resource that may support other retention activities. Overall, studies suggest that the effectiveness of using dictionaries is not necessarily tied to proficiency level but rather to being a skilled dictionary user and the type of task it is used to accomplish (e.g., comprehension versus production). Moreover, electronic versions of learner dictionaries may hold an advantage. Dziemianko (2010) found that intermediate and advanced learners showed better retention of meaning and recall of vocabulary and collocations during acquisition.

In this section we have suggested some reading-oriented activities that learners can do on their own. However, it is also important to remember that interaction is a key component of second language acquisition. Many libraries organize book clubs where L2 learners can engage in face-to-face discussion with a wider readership, including native speakers. Online book clubs may provide an option for participation via reading and writing in the L2.

\section{Technology-mediated Resources}

Technology-mediated engagement may include choosing the L2 option at ATMs, automated payment stations, or phone systems. (This, of course, depends on the language areas. English speakers of L2 French may easily find this option in Canada; English L2 speakers of Spanish will find this option at least in parts of the United States.) One may listen to podcasts, read public discussion forums on topics of interest, or follow websites, blogs, Instagram, or Twitter in a variety of languages; to convert listening into listening with a production activity, language retainers may undertake to respond to a posting and thus take part in a conversation. Retainers can play online games in the target language while communicating with other gamers. On the 
most independent end of the continuum, some retainers might start their own blog, Instagram posts, or podcast in their target language.

Before we consider online programs, websites and apps, which most people might think of as "technology," we first discuss technology-enabled enhancements made to videos and books.

Enhanced viewing. Although videos with text are not new to language learners, modern standards in web design, specifically in instructional contexts, promote accessibility in online environments (https://www.w3.org/). L2 learners can exploit authentic online materials, such as full-length movies, documentaries, short films, and cartoons, enhanced with captions and/or subtitles for independent study. Captions refer to text accompanying an audio-visual format in the same language and subtitles refer to text accompanying an audio-visual format in another language(s). Technology moves rapidly, and one example of this is that Netflix has recently released "Language Learning with Netflix," a Chrome extension designed to allow L2 learners "who already have some basic understanding of their language" to view video (of movies, films, and TV series) with simultaneous on-screen display of both the caption and the translation of the audio track in an increasing number of countries and languages (Lee, 2019). Several design features incorporated into the app are intended for tailoring its capabilities to the learners' needs, such as setting target vocabulary size, practicing pronunciation, or manipulating play-back speed. Finally, this app also includes a user guide, a resource that is often not included with other apps. Further development of this tool is ongoing; however, currently not much is known about its long-term effects on language learning.

Captions and subtitles may aid retainers in different ways, such as by segmenting the continuous speech flow, focusing their attention, and making more intelligible spoken accent variations (Vanderplank, 1993). Research on captions and subtitles shows their use increases motivation to learn and can result in positive gains in listening comprehension and vocabulary learning (Bird \& Williams, 2002; Gass, Winke, Isbell, \& Ahn; 2019; Perez, Van Den Noortgate, \& Desmet, 2013; Peters, Heynen, \& Puimège, 2016).However, the benefit of captions may be limited by certain factors such as the difference between the learner's L1 orthographic system and the L2 (at the lower proficiency levels), the learner's familiarity with content, and the vocabulary level. Gass et al. $(2019$, p.98) conclude that "captions are a powerful visual attraction even if one does not need them" and suggest they are most beneficial when the content and language of materials is within the range of the learner's current level of proficiency. Technological developments combined with the above findings may encourage learners of all levels of proficiency to consider audio-visual resources for self-study with captions and subtitles while viewing.

Enhanced reading. Learners can complement pleasure reading by simultaneously listening to the recorded version of a short story, as facilitated by audiobooks. Audiobooks engage learners' listening skills by delivering content on a computer or mobile device. Learners, depending on their proficiency and/or interest, may choose the listen-only mode. Accessible content can be downloaded from library websites or purchased online, or through pre-loaded audio devices such as Playaway. Chang (2009) suggests that such reading-while-listening activities increase word 
recognition skills and listening fluency, in addition to enhancing vocabulary. In their review of audiobooks in language teaching, Alcantud Díaz and Gregori-Signes (2014) cite research showing that audiobooks with content recorded by trained professionals can also serve as models of pronunciation and fluency.

Enhanced listening. In addition to audiobooks, listening content for L2 self-study is also accessible in the form of podcasts, and many podcast sites include transcripts of the podcasts. Podcast apps may also allow listeners to manipulate playback speed, and this, in turn, may improve word recognition and comprehension. To improve listening fluency (Rost, 2014) learners can benefit from listening to the target language spoken at a normal tempo and by listening to speakers representing different varieties of the target language.

One example of an opportunity for listeners to become creators of content may be found in the Voicemaps app. Van Zeijl (2013) describes this GPS technology-enabled app that allows individuals to record a narrated tour of their visits around the world (or one's own neighborhood, depending on the location). These narrated routes are complemented by virtual maps and pictures from the trip or location, and edited before publishing (voicemaps//me). Narrators are everyday travelers from around the world telling their stories in their own voices in English, including both native and non-native speakers. Retainers can be either listeners, producers, or both by publishing their stories online.

Apps and websites. Technology is a potentially valuable source for language learners that allows learners access to the target language and opportunities for learning anytime, anywhere, at their own level and pace (Larsen-Freeman \& Anderson, 2011). There are various online materials as well as a limited number of paid apps (or combination of free access and paid) such as Duolingo and Livemocha (two apps with linguists on their boards, although Livemocha has recently been retired). In this section we will examine online materials that have been evaluated for efficacy.

Reviewers of language learning apps include language teachers, language learners, and researchers who decide to try one or another of these platforms. Most reports include a description of the interface, type of materials and exercises afforded by the apps, and the users' experience. However, few provide an evaluation of the affordances of the app against principles of second language acquisition, and the actual efficacy of these apps is even less frequently backed up by empirical studies, as also noted by Lafford, Lafford, and Sykes (2007). Recognizing the updates of existing tools and rapid development of new ones, our goal here is to briefly point out some common themes without an exhaustive treatment and review of all available apps.

Language learning apps pride themselves on offering access to multiple languages. Depending on their purpose, they utilize different methods and materials to appeal to language learners and promote different skills. For example, Duolingo, offers language practice in the form of translation-based activities complemented by grammar and vocabulary exercises, and it is often evaluated as 'for beginners.' Live mocha emphasized the role of peers in language learning. In their speaking and writing activities, learners recorded parts of a text or submitted a 
prompt-based essay and received feedback from their peers; they could also engage with native and/or nonnative speakers to practice dialogues (Jee \& Park, 2009). The Tandem Language Exchange app emphasizes interaction by offering an opportunity to chat with native speakers. Among the advantages of these different apps, cost-free access is often cited. However, access to the paid version of the same app may provide access to different types of exercises and materials (Liaw, 2011). Apps promote motivation through their game-like design, and potentially further self-autonomy by advising learners to monitor their progress and choose content that meets their goals and needs (Lloyd, 2012).

In a study of 85 learners of Spanish using Babbel, Loewen, Isbell, and Sporn (2018) reported $32 \%$ attrition of learners ( 58 of 85 by the time of the posttest). Learners who persisted had previous Spanish experience ( 2 years of Spanish at high-school or college level). Given previous experience, they moved from novice to novice-low or novice-mid, and a few to intermediate. Relevant to language retention, another efficacy study on Babble (Vesselinov \& Grego, 2016) found that 18.4 hours of engagement were needed to maintain proficiency, and another 10 hours, more than 19.2 hours on average, were required for positive gain.

At least some apps have relatively low efficacy, whether from the design of the app or the difficulty for learners to stay motivated. Cunningham (2015) observed that apps target learners with existing motivation and curiosity similar to what Kormos and Csizér's (2014) model predicts. Nielsen (2011) reported on a study conducted with US government employees, who were encouraged to study an L2 independently using the Rosetta Stone (RS) and Tell Me More (TMM) apps for oral language development. The original plan asked employees to study with RS 10 hours/week over 20 weeks and with TMM for 5 hours/week for 26 weeks. Findings reported a large reduction in participants and small proficiency gains for those who endured. When asked about dropping out, many (former) participants cited change of plans and conditions at work, lack of vocabulary relevant to job (which was the initial purpose of learning the language), not liking the app, or unreliable access to technology when traveling. Comparing feedback from participants studying different L2s revealed that the quality of the materials differed by language. Employees also reported that the app-based materials required supplemental sources, such as consulting dictionaries and/or native speakers, and online grammar guides. Absolute zero L2 learners also explained the lack of directions as a barrier to engagement. Some successes were also reported: one participant who spent 200 hours with RS moved from zero-beginner to novice-high in oral proficiency. After spending 134 hours over six months with the app, novice learners improved on vocabulary and pronunciation but not on sentence-level production.

Gaming. Gaming, the participation in virtual games such as Second Life, Quest Atlantis, and World of Warcraft, is an activity in which aspiring retainers can engage using their L2. Gaming is a motivating activity for many adults, independent of other goals. In multiplayer games, players engage with each other in a quest; during these games, the focus is on creating knowledge through social interaction. Players communicate both synchronously and asynchronously, e.g. via text and voice chats, using conversational language as well as highly 
sophisticated, academic language (Gee, 2012, Edutopia Lecture). Thorne, Fischer, and Lu (2012) found that World of Warcraft, for example, is extremely rich in low-frequency, sophisticated words, syntactically complex sentences, and sentences that vary in length and incorporate multiple structures. Empirical studies have shown that these games increase motivation, develop L2 vocabulary, communicative competence (Peterson, 2010), listening skills (Levak \& Son, 2017), and self-efficacy beliefs (Henderson, Huang, Grant, \& Henderson, 2009), and thus seem to be promising communicative contexts for retention.

Both traditional and technology-mediated resources and activities offer opportunities for input, interaction, and production that may facilitate L2 retention. In the next section we discuss ways in which teachers might work with learners to prepare them for retention.

\section{Educating Teachers, Educating Learners}

Cohen (2018) suggests that teachers should "alert learners to the challenges involved in maintaining language skills over time" (p. 8). In order to do that, teachers need to have information about attrition, which means that we need to include information on attrition in language teacher education courses. Teachers who understand attrition issues may be able to help learners prepare for retention. Although the learning will take place outside the classroom, teachers play an important role in preparing learners for self-study by incorporating various activities including digital literacy training into their teaching. Instructors have been found to influence student motivation as well as attitudes toward technology.

Motivation is a complex and dynamic process that changes over time, and it can also be developed. L2 instructors can introduce various activities and strategies into classroom instruction that develop and help maintain motivation, as shown in hands-on activities and techniques reported by Hadfield and Dörnyei (2014). (See also Csizér \& Illés, this issue.) The willingness to invest energy into self-study requires a learner who can set goals, has a study plan, and applies motivating strategies to counter boredom and other obstacles (Kormos \& Csizér, 2014).

Learners need to be taught explicitly how to navigate tools and engage with them. Before students undertake language learning in the digital space, instructors can help them develop information literacy skills which may require explicit training for even high school and college age students (Burghardt \& Wray, 2016). The variety of available study materials and aids, such as dictionaries, apps, and websites, require learners who are able to locate and evaluate such materials before making a choice, or, to choose legitimate language partners online. ${ }^{\text {ii }}$ Chen (2016) presents a theoretically-motivated checklist for evaluating mobile technologies and their utility with an analysis of seven apps, which can also be used to practice app evaluations in class. In addition to building general awareness of available materials and activities for autonomous learning, a classroom could incorporate a unit at the end of a semester (or end of a program) that focuses on retention.

Preparing learners for retention. While learners are still in class or in a program, teachers or directors can assist them in making individual retention plans (students who are pursuing further 
education in L2 or taking a job using L2 could do a modified assignment). In this section, we return to an early concern of attrition studies, namely the potential for attrition during summer vacation. We use preparing for summer vacation as an illustration of how teachers can help students develop a learning plan to promote retention for a well-defined period. Having a plan may help learners set realistic goals, stay motivated, and have a positive experience.

We illustrate a menu that might help students prepare a customized language plan that meets their goals, needs, and also considers their interests.

My language retention plan

My language goals are:

My teacher estimates my level is:

My plan is for (how long?):

Protip:

- Use strategies learned in the language class when working with materials.

- Don't work alone all the time: incorporate activities that involve interaction.

- Keep up all skills.

- Remember: repetition and memorization alone are limited.

- Be informed about various tools, e.g. software, apps. Research who they are designed for and what they are (not) designed to do.

What's your reading plan?

My teacher recommends that I read:

I would like to read:

What's your listening plan?

What's your interaction plan?

Protip: When interacting via the web, know who you are talking to.

Have a plan for online conversation meetings and follow it.

Where will you find opportunities, resources, and tools?

Protip: Explore the diversity of your local community (or if you are returning home, your home community). You may find free conversation practice events at the following places:

- $\quad$ Local library (visit, call, online), community centers, community colleges, adult learning centers may offer conversational language classes in your L2.

- Area schools and other educational institutions - for example, some universities have visiting scholars and/or international student organizations with native speakers of your target L2 who may be interested in having a conversation partner.

- College language programs often organize conversation events that are open to the public, such as 'coffee hour,' or 'tea hour,' where you can connect and find a tutor or language exchange partner.

- $\quad$ Churches, synagogues, mosques, and other faith-based communities may offer events or services in yourL2.

Read the local newspaper, search online to find out if your local community has an L2 group close by. Then join them. Note that these groups can be found sometimes only by word of mouth, so you need to stay committed to your search.

What will you do for continued learning or accountability purposes?

Protip: Consider choosing a language study buddy in your class or at the workplace, who is interested in 
maintaining or increasing their language skills.

What is your contingency plan?

- What foreseeable events do you know that may disrupt your study plan, e.g. work, family, travel?

- What will you do to stay on track during this time?

Choose one word that best describes how motivated are you to get started.

Good luck!

\section{Future Research}

Cohen (2018) proposed that research should address the effect of retention activities: "It would seem beneficial for research to look at the best ways for learners to maintain their control of the L2 rather than to attrite" (p. 9). We agree whole-heartedly! In this paper we have suggested ways in which learners might use traditional and technology-mediated resources and activities to promote retention, weighing the suggestions based on their reported efficacy for language learning. To our knowledge, there is no specific research on how well any of these suggestions work as retention activities. For example, in the case of the retention module created by Ludwig et al. (2009), Ludwig and colleagues tested the prototypes, but were not able to test the long-term effect on the population for which the games were designed. Research will also have to take into account that retention is a particular challenge because learners are often isolated, and this may require particular commitment and motivation.

It is not our goal to develop research questions here, but we note that there are resources to consult when undertaking such investigations. Bardovi-Harlig and Stringer (2010) discuss issues concerning research on attrition and retention. Reinders and Benson (2017) have developed a research agenda for examining learning beyond the classroom, addressing how to evaluate the learning outcomes of activities similar to the ones discussed here. A judicious combination of suggestions from both sources could offer a good starting point. One of the challenges of retention is that it is potentially open-ended. If we implement a class-supported retention unit of the type that we have described, with learners who plan to return after summer vacation, that would allow us to identify both a sample population of retainers and an endpoint for the study.

\section{References}

Alcantud Díaz, M., \& Gregori-Signes, C. (2019). Audiobooks: Improving fluency and instilling literary skills and education for development. Tejuelo, 20, 111-125.

Al-Homoud, F., \& Schmitt, N. (2009). Extensive reading in a challenging environment: A comparison of extensive and intensive reading approaches in Saudi Arabia. Language Teaching Research, 13, 383-401.

Bardovi-Harlig, K., \& Stringer, D. (2010). Variables in second language attrition: Advancing the state of the art. Studies in Second Language Acquisition, 32, 1-45.

Başal, A., Aytan, T.,\& Demir, I. (2016). Teaching vocabulary with graphic novels. English Language Teaching, 9, 95-105. 
Bird, S. A., \& Williams, J. N. (2002) The effect of bimodal input on implicit and explicit memory: An investigation into the benefits of within-language subtitling. Applied Psycholinguistics, 23, 509-533.

Burghardt, B. \& Wray, C. C. (2016, March). Integrating information literacy into the Level 5 reading-writing and L5 academic skills classes: An instructional manual. Retrieved from http://hdl.handle.net/2022/21597

Chang, C. S. (2009). Gains to L2 listeners from reading while listening versus listening only in comprehending short stories. System, 37, 652-663.

Chun, C. W. (2009). Critical literacies and graphic novels for English $\square$ language learners: Teaching Maus. Journal of Adolescent \& Adult Literacy, 53, 144-153.

Clark, J.D. L., \& Jorden, E. (1984). A study of language attrition in former U.S. students of Japanese and implications for design of curriculum and teaching materials. Final project report. Center for Applied Linguistics, Washington DC. ERIC document 243317.

Cohen, A. D. (1974). The Culver City Spanish Immersion Program: How does summer recess affect Spanish speaking ability? Language Learning, 24, 55-68.

Cohen, A. D. (1975). Forgetting a second language. Language Learning,25, 127-138.

Cohen, A. D. (1986). Forgetting foreign language vocabulary. In B. Weltens, K. de Bot, \& T. J. M. van Els (Eds.), Language attrition in progress (pp. 143-158). Dordrecht: Foris.

Cohen, A. D. (1989). Attrition in the productive lexicon of two Portuguese third language speakers. Studies in Second Language Acquisition, 11, 135-149.

Cohen, A. D. (2010). Focus on the language learner: Styles, strategies and motivation. In N. Schmitt (Ed.), An introduction to applied linguistics (pp. 161-178). London: Hodder Education.

Cohen, A. D. (2018). Reflections on a career in second language studies: Promising pathways for future research. $L 2$ Journal, 10, 1-19.

Cunningham, K. J. (2015). Duolingo. TESL-EJ 19. Retrieved January 14, 2020 from http://www.teslej.org/pdf/ej73/m1.pdf

Csizér, K., \& Dörnyei, Z. (2005). The internal structure of language learning motivation and its relationship with language choice and language effort. The Modern Language Journal, 89, 19-36.

Day, R. R.,\& Bamford, J. (1998). Extensive reading in the second language classroom. New York: Cambridge University Press.

de Bot, K., \& Stoessel, S. (2000). In search of yesterday's words: Reactivating a long-forgotten language. Applied Linguistics,21, 364-384.

Dörnyei, Z., \&Ushioda, E. (2013). Teaching and researching motivation. New York: Routledge.

Dziemianko, A. (2010). Paper or electronic? The role of dictionary form in language reception, production and the retention of meaning and collocations. International Journal of Lexicography, 23, 257-273.

Edutopia. (2012, March 21). James Paul Gee on learning with video games [Video file]. Retrieved December 18, 2019 from https://youtube/JnEN2Sm4IIQ

Gass, S., Winke, P., Isbell, D. R., \&Ahn, J. (2019). How captions help people learn languages: A working-memory, eye-tracking study. Language Learning \& Technology, 23, 84-104.

Gardner, R. C., Lalonde, R. N., \& MacPherson, J. (1985). Social factors in second language attrition. Language Learning, 35, 519-540.

Gardner, R. C., Lalonde, R. N., Moorcroft, R., \& Evers, F.T. (1987). Second language attrition: The role of motivation and use. Journal of Language and Social Psychology, 6, 29-47.

Grabe, W.,\& Stoller, F. (2002). Teaching and researching reading. Harlow: Longman

Hadfield, J., \& Dörnyei, Z. (2014). Motivating learning. London: Routledge 
Hansen, L., Umeda, Y., \& McKinney, M. (2002).Savings in the relearning of second language vocabulary: The effects of time and proficiency. Language Learning, 52, 653-678.

Henderson, M., Huang, H., Grant, S., \& Henderson, L. (2009). Language acquisition in Second Life: Improving self-efficacy beliefs. In R. Atkinson \& C. McBeath, Same places, different spaces. Proceedings ascilite Auckland 2009 (pp. 464-474).Auckland, New Zealand: Auckland University of Technology. Retrieved January 14, 2020 from http://www.ascilite.org.au/conferences/auckland09/procs/henderson.pdf

Hosler, J., \& Boomer, K. B. (2011). Are comic books an effective way to engage nonmajors in learning and appreciating science? CBE Life Sciences Education, 10, 309-317.

Jee, M. J.,\& Park, M. J. (2009). Livemocha as an online language-learning community. CALICO Journal, 26, 448456.

Kormos, J., \&Csizér, K. (2014). The interaction of motivation, self-regulatory strategies, and autonomous learning behavior in different learner groups. TESOL Quarterly, 48, 275-299.

Krashen, S. (1989). Language teaching technology: A low-tech view. In J.E. Alatis (Ed.), Georgetown University Roundtable on Languages and Linguistics1989 (pp. 393 - 407). Washington DC: Georgetown University Press.

Lafford, B., Lafford, P., \& Sykes, J. (2007). Entre dicho y hecho...: An assessment of the application of research from second language acquisition and related fields to the creation of Spanish CALL materials for lexical acquisition. CALICO Journal, 24, 497-529.

Larsen-Freeman, D., \& Anderson, M. (2011). Techniques and principles in language teaching (3rd ed.). Oxford: Oxford University Press.

Lee, D. (February 12, 2019). This Chrome extension lets you learn a new language by watching Netflix. Retrieved January 16, 2020 from The Verge website: https:/www.theverge.com/2019/2/12/18220289/language-learningnetflix-chrome-extension-two-subtitles

Levak, N., \& Son, J. (2017). Facilitating second language learners' listening comprehension with Second Life and Skype. ReCALL, 29, 200-218.

Liaw, M. (2011). Review of Live mocha. Language Learning \& Technology, 15, 36-40.

Liu, J. (2004). Effects of comic strips on L2 learners' reading comprehension. TESOL Quarterly, 38, $225-243$.

Lloyd, E. (2012). Language learners' willingness to communicate through livemocha.com. Apprentissage des Langues et Systèmesd' information et de Communication (ALSIC), 15.Retrieved January 18 from http://journals.openedition.org/alsic/2437.

Loewen, S., Isbell, D. R., Sporn, Z. (2018). Learning Spanish with Babbel. Babbel white paper. Retrieved March 16, 2020 from https://press.babbel.com/en/downloads/studies_research/.

Ludewig, J. (2017). A look over the wall: Using the graphic novel drüben! to teach linguistic, literary, cultural, and visual skills. Die Unterrichtspraxis/Teaching German, 50, 162-170.

Ludwig, J., Fu, D., Bardovi-Harlig, K., \& Stringer, D. (2009). Serious games for second language retention. Proceedings of the Industry/Interservice, Training, Simulation \& Education Conference (I/ITSEC 2009), 1-10.

Moeller, A. K. \& Meyer, R. J. (1995). Children's books in the foreign language classroom: Acquiring natural language in familiar contexts. Faculty Publications: Department of Teaching, Learning and Teacher Education, 164. Retrieved December 10, 2019 from https://digitalcommons.unl.edu

Nielsen, K. (2011). Self-study with language learning software in the workplace: What happens? Language Learning \& Technology, 15, 110-129.

Perez, M. M., van den Noortgate, W., \& Desmet, P. (2013). Captioned video for L2 listening and vocabulary learning: A meta-analysis. System, 4, 720-739.

Peterson, M. (2010). Massively multiplayer online role-playing games as arenas for second language learning. Computer Assisted Language Learning, 23, 429-439. 
Peters, E., Heynen, E., \& Puimège, E. (2016). Learning vocabulary through audiovisual input: The differential effect of L1 subtitles and captions. System, 63, 134-148.

Reinders, H., \& Benson, P. (2017). Research agenda: Language learning beyond the classroom. Language Teaching, 50, 561-578.

Rost, M. (2014). Developing listening fluency in Asian EFL settings. In Muller T., Adamson J., Brown P.S., \& S. Herder (Eds.), Exploring EFL fluency in Asia (pp. 281-296). London: Palgrave Macmillan.

Russell, R. A. (1999). Lexical maintenance and attrition in Japanese as a second language. In L. Hansen (Ed.), Second language attrition in Japanese contexts (pp. 114-141). Oxford, England: Oxford University Press.

Thorne, S. L., Fischer, I., \& Lu, X. (2012). The semiotic ecology and linguistic complexity of an online game world. ReCALL Journal, 24, 279-301.

University of Oregon Center on Teaching and Learning. Big ideas in beginning reading. Retrieved January 11, 2020 from http://reading.uoregon.edu/big_ideas/.

Vanderplank, R. (2003). 'Pacing' and 'spacing' as predictors of difficulty in speaking and understanding English, ELT Journal, 47, 117-125.

Vesselinov, R. \& Grego, J. (2016).The Babbel efficacy study. Babbel white paper. Retrieved March 16, 2020 from https://press.babbel.com/en/downloads/studies_research/.

W3C. (2012). Accessibility, usability, and inclusion. Retrieved January 22, 2020 from https://www.w3.org/standards/

Williams, N. (1995). The comic book as course book: Why and how. [Lecture]. 29th Annual TESOL Convention. Long Beach, CA, March 26-April 1, 1995. Retrieved January 12, 2020 from http://eric.ed.gov/?id=ED390277

van Zeijl, M. (2013). The Soundwalker in the street: Location-based audio walks and the poetic re-imagination of space. In De Michelis, G., Tisato, F., Bene, A., \& D. Bernini (Eds.), Arts and Technology: ArtsIT 2013 (pp. 1724). Berlin: Springer.

iSee also Reinders \& Bensen (2017) for a description of "learning beyond the classroom" (LBC) and relevant activities.

iiThere are a variety of bilingual books written for young children that language learners with beginner level proficiency might also benefit from. Such literature is illustrated with pictures and exposes learners to "more than just vocabulary - it involves syntax" presented in "natural language in familiar contexts" (Moeller\& Meyer, 1995, p. 34). Learners with families may also want to plan retention activities for their children.

iiiThere have been warnings posted online about potential online interlocutors even on language learning websites. Users should always exercise caution; teachers should warn students to do so, especially if supervising minors. 